\title{
OP-06 EFFECT OF THE NATIONAL RURAL HEALTH MISSION ON INSTITUTIONAL DELIVERIES AND RELATED OUT-OF-POCKET SPENDING BY THE POOR
}

Pallav Bhatt, Digvijay Singh Sandhu. PHFI - Public Health Foundation of India, Gurgaon (Haryana), India.

\subsection{6/bmjgh-2016-EPHPabstracts.6}

Background The National Health Mission (NHM) is an effort to increase public spending for strengthening health system. Initially this programme, launched in 2005, was named National Rural Health Mission and implemented only in rural areas. Later in 2013, the programme was expanded to urban areas and renamed NHM. Two major components of NHM are 'Reproductive and Child Health (RCH) flexipool' and 'Mission flexipool'. It has been observed that institutional deliveries have increased from $50 \%$ in 2008-2009 to $65.08 \%$ during 20142015. The objective of this study is to evaluate whether the increase in government expenditure under NHM has benefited all classes of the society equally. Have the poor and vulnerable sections benefited from the increased funding under NHM?

Methods Our research was conducted in two phases. In the first phase we analysed trends and patterns of health expenditure by the national government using data from the national budget as well as financial information about NHM available in the public domain. In the second phase, we studied the health financing system in the public sector with special focus on $\mathrm{RCH}$ flexipool and Mission flexipool along with out-of-pocket (OOP) spending across different socio-economic groups. The National Sample Survey 60 th and 71 st round have been used to estimate OOP spending during child birth, antenatal and postnatal care in public health institutions.

Findings and discussion Expenditure on $\mathrm{RCH}$ flexipool and Mission flexipool has increased by $243 \%$ and 291\% respectively during the period from 2007-2008 to 2013-2014, with comparatively higher funds going towards Empowered Action Group states. Substantial increase in public expenditure has been reflected as an increase in institutional delivery in public healthcare facilities. However, the fund has not been equitably distributed among different sections of society. Specifically, change in OOP spending for childbirth in public institutions was the maximum for the poorest class (56\% increase) compared to a $3 \%$ decrease in OOP spending for the highest income group. The increase in total OOP spending for pre- and postnatal care is comparatively higher for the poorest quintile in Empowered Action Group states than for the richest quintile. It is evident from the results that increase in public expenditure on health has improved utilisation of public institutions by the 
poor. However, increased public expenditure on health did not improve financial risk protection nor did it solve the (in)equity problem in health expenditure for reproductive and child health services. The transition has adversely affected the poor by increasing the burden of OOP spending burden, even in public institutions.

No competing interest. 